the East, provides an authoritative assessment of most of the problems which have a direct bearing on milk production, whether geographical, soil and climate, grassland, fodder, animal husbandry, or economic. This assessment should be of special value to the advisers of such governments of developing countries as are genuinely interested in the nutrition of their children and of their population generally, and who are willing to do something about it.

Dr Whyte's analysis and well-documented proposals, which he supports by figures which are probably as near the mark as statistics from underdeveloped countries are likely to be, will meet with little criticism from those with experience of these countries. He gives two numerical items, however, which eatch the eye: on page 167 "over 80 per cent of the milk produced in India comes from buffaloes"-.-this is surely a misprint; the figure given recently by other authorities is between 55 and 60 per cent. In describing milk production in Tunisia on page 136 , 5,000 dairy cattle and 130,000 dual purpose cattle are mentioned, but nothing is said about the 380,000 buffaloes $^{1}$ which must also contribute substantially to the Tunisian milk supply.

'FAO Production Yearbook, 19, 190 (1965).

\section{INSECT ECOLOGY}

\section{The Ecology of Insect Populations in Theory and Practice}

By L. R. Clark, P. W. Geier, R. D. Hughes and R. F. Morris. Pp. xiii + 232. (London: Methuen and Co., Ltd.; distributed in the USA by Barnes and Noble, Inc., 1967.) $45 s$. THIs book, written by four experienced insect ecologists from different continents, cannot and does not fail to be extremely valuable. It is recommended at some stage of their careers to all who are interested in insect ecology.

A combination of authors, however, in ironing out each other's opinions, also carries the possible hazard of underemphasis in striking a line for the uninitiated. For this reason the reader must either start with opinions which the book will undoubtedly modify, or be patiently prepared to read repetitively in order to erect a basic and biased set of opinions from which further consideration can lead to true appreciation.

The system adopted in this book of presenting, often usefully by quotation rather than mere reference, a set of diverging opinions followed by a discussion, is attractive but may in some cases be spoiled by a lack of final opinion especially if the reader is a beginner. A more extensive treatment would have been welcome in spite of the comment in the preface that principles only would be discussed.

The two introductory chapters are excellent in clarifying the idea of the "life system" approach to the greater dynamic equilibria. Similarly, the third chapter, "Current Theories to explain Insect Numbers", is a really fine précis of a voluminous literature. It is true that there is scope here for disagreement, that quotation is selective and does not bring out this or that point, but by and large a good bird's-eye view emerges.

On the other hand, the fourth chapter, "The Functioning of Life Systems" ( 89 pages), is at once interesting and all important, but to some people will be slightly exasperating. Certain readers would prefer a more unified approach to each case, possibly summarized by diagrams and followed by an overall discussion, whilst others, including myself, would prefer it as it is. In any case, however, the reforences are ample and the wide selection of types reviewed is gratifying. This chapter must constantly be reviewed because herein lies the "proof of the pudding". Never is this more true than when reading on to the "Ecology of Pest Control", the sixth chapter, and "The Further Development of Research on Insect Populations", the seventh chapter.

Having completed one's reading and started to ponder, one inevitably becomes aware of the lack of a subject index. It is true that individual ideas can be traced if one remembers a biological name, a used term or an author, but if one only has a hazy idea, for example, "that it had something to do with DD'T or an insecticide". some chasing backwards and forwards is necessary.

It now remains to state an exceedingly important characteristic of this book, which is to aid in sorting out the exceedingly numerous facets of ecology. Again and again as I read and decided that some aspect was missing, such as genetics under-emphasized, I checked and decided that it was indeed raised and relegated reasonably to certain areas, and that to go further would have required a book on the principles of biology rather than the ecology of insect populations. Similarly with the influence of behaviour and physical factors on population problems to those particularly interested in such factors. As an example, there is the reference on page 24 to the inevitability of population survival due to the average prevailing consistency of locust swarm drop in favourable wet front areas. I eventually had to concede that it is (a) mentioned and $(b)$ perhaps does not require emphasis in this book. As the authors say on page 34, "because our" interest is focused on populations, we find it useful 10 think of demographic occurrences as primary events and those which affect or qualify as secondary events". Ecologists whose interests are otherwise will find this attitude a corrective influence.

Finally there is much to stimulate those concerned with pest control. The approach of "protective management" favoured by most ecologists as against species eradication is realistically discussed in a stimulating manner. Although a plea for future work towards this end is made, the reader is reminded of the ever present threat to such schemes which may result from unpredictable evolutionary occur rences. This appears to be a salutary warning that to proceed slowly is to proceed wisely.

The production of this book is excellent and printing errors are minimal.

F. L. WATERHOUSE

\section{BIOLOGICAL OCEANOGRAPHY}

\section{Aspects of Marine Zoology}

Edited by N. B. Marshall. (The Proceedings of a Sym. posium held at the Zoological Society of London on 23 and 24 March 1966. Symposia of the Zoological Society of London, No. 19.) Pp. $x+270$. (London: Academic Press, Inc. (London), Ltd.; New York: Academic Press, Inc., 1967. Published for the Zoological Society of London.) $80 s . ; \$ 14$.

$I_{T}$ is to be both welcomed and expected that the advances in underwater technology that have occurred during the past decade are leading to a re-orientation of the traditional approach to the study of the organisms living in the deeper parts of the oceans. This book probably marks the beginning of a period when greater scientific effort than ever before will be devoted to the study of the biolog. of these organisms rather than their morphology and taxonomy.

Those who are familiar with the books by Beebe and Cousteau will have been introduced to a world where the light intensity rapidly falls with incroasing depth until, at about 1,000 metres, the faint blue light from above is no longer adequate for visual purposes. C. M. H. Harrisson gives an interesting and comprehensive account of the methods used for sampling mesopelagic fish, assessing the merits of each type of gear while stressing the difficulties in obtaining a representative sample from such large, volumes of water unless several methods are uscd. In this twilight region and below, the majority of the fish earry luminous organs of one kind or another, and the varicty and function of these are reviewed by $J$. A. C. Nicol. As he points out, most of the specimens are dead 